\title{
Une Miliaire D'étiologie Inhabituelle: Leptospirose pulmonaire [A miliary of unusual etiology: Pulmonary Leptospirosis]
}

Nahid Zaghba, Hind Bakkal*, Hanane Benjelloun, Najiba Yassine

Service de Pneumologie, Faculté de médecine et de pharmacie/ Université Mohammed V /centre hospitalier Ibn Rochd/ Rue des Hôpitaux Casablanca 20360/ Casablanca, Marocoo

DOI: $10.36347 /$ simcr.2020.v08i06.011

| Received: 28.02.2020 | Accepted: 06.03.2020 | Published: 20.06.2020

*Corresponding author: Hind Bakkal

Abstract

Case Report

Leptospirosis is an under-diagnosed anthropozoonosis of global distribution. It presents clinical manifestations of variable severity ranging from a flu-like syndrome, the most common form and good prognosis, to multi-visceral involvement. Whose typical clinical form is Weil's syndrome associating fever, jaundice, renal failure and diffuse hemorrhagic signs. Pulmonary involvement is rare and can be serious and is complicated by respiratory distress syndrome and intra-alveolar hemorrhage. We report a clinical case of pulmonary leptospirosis, in a 28 -year-old man, whose presentation was that of a severe pneumopathy associated with hemoptysis, with presence of jaundice. Our article reminds us that we must think of a pulmonary form of leptospirosis in front of a severe pneumopathy with hemoptysis, especially in the presence of a risk of contamination, even in the absence of liver injury. But the polymorphous presentation sometimes makes the clinical diagnosis difficult.

Keywords: Hemoptysis; icterohaemorrhagic fever; bronchoscopy; serodiagnosis; Martin and Petit.

Copyright @ 2020: This is an open-access article distributed under the terms of the Creative Commons Attribution license which permits unrestricted use, distribution, and reproduction in any medium for non-commercial use (NonCommercial, or CC-BY-NC) provided the original author and source are credited.

\section{INTRODUCTION}

Leptospiroses are anthropozoonoses caused by spirochaetes of Leptospira, the most common one is ictero-haemorrhagiae $[1,2]$. Pulmonary affection during leptospirosis can be serious, caused by intravenous haemorrhage. alveolar and respiratory distress syndrome, hence its seriousness. It can be associated to multi-visceral failure [1-3]. We report a case report of pulmonary leptospirosis, in a 28 -year-old man, who showed out severe pneumopathy associated to hemoptysis, as well as jaundice. Our article underlins that we must think of pulmonary leptospirosis form when ever there is severe pneumopathy with hemoptysis, especially in case of contamination risk background.

\section{Case Report}

It is about a 28-year-old man, night keeper in a sugar factory, of low socio-economic level. He lived in a slum in Casablanca. He was a chronic, three-pack, chronic cannabic tobacco addict, with no known tuberculous contagion and no other particular pathological antecedent.

He showed out, seven days before his hospitalization, bronchial syndrome with cough and purulent sputum with minimal daily hemoptysis associated with effort dyspnea quickly worsening, becoming lipothymies at rest, myalgia and widespread pruritus. The All developing in a feverish context and general health impairement. The examination found out a weakened patient (PS at 3), diffuse cutaneo-mucous jaundice, polypnea at 30 cycles / min, fever at $39^{\circ} \mathrm{C}$, dark urine, discolored stools with microscopic hematuria with urine strips. Pleuro-pulmonary examination was normal, as well as the somatic examination. Chest X-ray (Fig 1a) showed diffuse bilateral diffuse-micronodular opacities predominant at the basal level. The chest CT scan (Fig 2) showed bilateral basal interstitial syndrome.

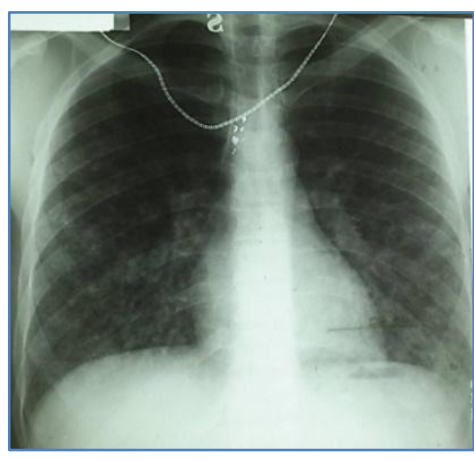

Fig-1a: Chest $x$-ray on admission 


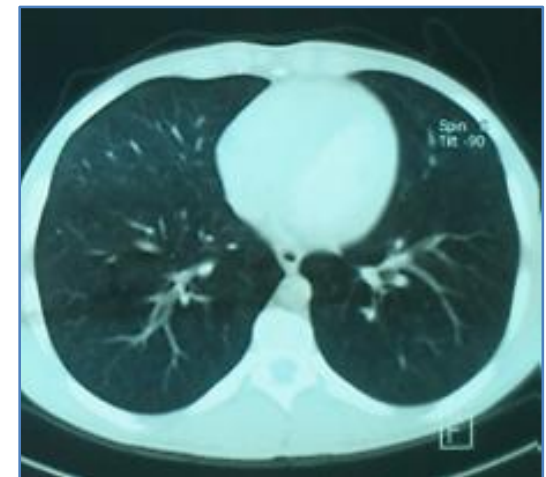

Fig-1b: Chest computed tomography on admission

The red blood cell count underlined leukocytosis at $33750 / \mathrm{mm} 3$ with a neutrophils predominance $(\mathrm{PNN})$ at $27191 / \mathrm{mm} 3$, and thrombocytopenia at $70000 / \mathrm{mm} 3$. The transaminases were elevated, aspartate amino transferase (ASAT) at 104 IU / $1(3 \times N)$; alanine aminotransferase (ALT) at $126 \mathrm{IU} / 1(3 \times \mathrm{XN})$, total bilirubin $(\mathrm{BT})$ at $591 \mathrm{mg} / 1$ $(12 \mathrm{xN})$, bilirubin conjugate $(\mathrm{BC})$ at $448 \mathrm{mg} / 1(149 \mathrm{xN})$, gammaglutamyl transferase ( $\delta \mathrm{GT})$ ) at $46 \mathrm{IU} / 1$, creatine phosphokinase (CPK) at 62 IU / 1 (N <113), urea at $1.26 \mathrm{~g} / 1$, serum creatinine at $13.6 \mathrm{~g} / 1$ and CRP. 1. Tuberculin intradermal reaction and bacilloscopies were negative. Sterile blood cultures and ECBU.

The viral hepatitis serologies A and B were negative. Abdominal ultrasound, echocardiogram and electrocardiogram were also normal.

The red blood cell count underlined leukocytosis at $33750 / \mathrm{mm} 3$ with a neutrophils predominance (PNN) at $27191 / \mathrm{mm} 3$, and thrombocytopenia at $70000 / \mathrm{mm} 3$. The transaminases were elevated, aspartate amino transferase (ASAT) at $104 \mathrm{IU} / 1(3 \mathrm{xN})$; alanine aminotransferase (ALT) at $126 \mathrm{IU} / \mathrm{l}(3 \mathrm{xN})$, total bilirubin $(\mathrm{BT})$ at $591 \mathrm{mg} / 1$ $(12 \mathrm{xN})$, bilirubin conjugate $(\mathrm{BC})$ at $448 \mathrm{mg} / \mathrm{l}(149 \mathrm{xN})$, gammaglutamyl transferase ( $\delta \mathrm{GT})$ ) at $46 \mathrm{IU} / 1$, creatine phosphokinase (CPK) at $62 \mathrm{IU} / 1(\mathrm{~N}<113)$, urea at $1.26 \mathrm{~g} / 1$, serum creatinine at $13.6 \mathrm{~g} / 1$ and CRP. 1. Tuberculin intradermal reaction and bacilloscopies were negative. Sterile blood cultures and urine culture.

The viral hepatitis serologies A and B were negative. Abdominal ultrasound, echocardiogram and electrocardiogram were also normal.

Mycoplasma serology was negative, whereas Martin and Petit microagglutination serology was positive for Leptospira Interrogans (Copenhageni: 1600, Canicola 200 and Pomona 200) and Leptospira Biflexa (Patoc 800), the line being 100. leptospira and legionella test in the urine was negative leptospirosis diagnosis with pulmonary affection was highlighted.
The patient was administered bi-antibiotic therapy with Ceftriaxone $2 \mathrm{~g} /$ day for 10 days and Gentamycin $160 \mathrm{mg} /$ day for 5 days with rehydrating.

48-hours later, the evolution noted clinical improvement with apyrexia, dyspnoea and jaundice decrudescence, and haemoptysis resolution.

Biologically, reduced leukocytosis (leucocytes at 10,000 with $5000 \mathrm{PNN}$ ), the CRP was $4 \mathrm{mg} / 1$ and the platelet count was $357000 / \mathrm{mm} 3$. Transaminases also decreased (ASAT at $51 \mathrm{IU} / \mathrm{l}$ ) and conjugated bilirubin was $34 \mathrm{mg} / 1$.

Chest X-ray (Fig 2) after 10 days of treatment showed interstitial syndrome disappearance.

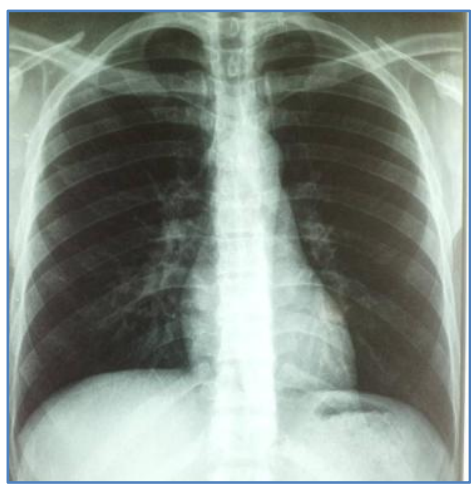

Fig-2: Control chest X-ray

Retrospective interview did not find out any risk factors for the patient's exposure to leptospirosis except for his unvaccinated dog against leptospirosis, his work as night keeper in the sugar factory with a significant risk rats presence, as well as poor habitat conditions. The patient's clinical examination did not find a lesion or skin injury at the time of admission. However, the patient was informed of the importance of a healthy lifestyle, the rat control and vaccination of dogs against leptospirosis.

\section{DISCUSSION}

Considered as professional disease (sewer disease), leptospirosis is currently an infectious disease spreading, particularly in tropical countries, but also in deprived suburbs of big cities [1], as was the case of our patient from a deprived community, living in the suburbs of Casablanca. The most concerned age group is the 20-60 age group, which accounts for $80 \%$ of the cases. There is an increase in women among leptospirosis cases, but they remain largely in the minority [2].

Leptospiroses are anthropozoonoses caused by spirochaetes of leptospira model, the most common is ictero-haemorrhagiae. Contamination is most often indirect in water environment. Animals (rats, cattle, dogs ...) removing leptospires through their urine contaminating the environment and water. In this 
background, a cutaneous lesion is an issue [2- 4]. The incubation usually lasts six to 14 days, and leptospirosis shows out most often as hepato- nephritis [3].

Leptospirosis has a very variable clinical feature since the flu-like syndrome (fever, nausea, myalgia, vomiting, abdominal pain, rashes) good prognosis to the multi-organ involvement whose typical clinical form is Weil syndrome associating fever , jaundice, renal failure and diffuse hemorrhagic signs.

Other organs may be affected by multi-organ failure including the life-threatening lung, heart and meninges [5]. Our patient had pulmonary and hepatic leptospirosis with low-grade hemoptysis, severe dyspnea, jaundice fever, and cholestasis syndrome without renal affection.

Pulmonary forms have long been considered exceptional in leptospirosis in temperate areas, whereas alveolar haemorrhages were frequent in the tropics ones [1] [4]. This location is extremely serious and would be burdened with high mortality $[3,5]$.

Acute pulmonary determinations of leptospirosis are rare, as highlighted by El Ouazzani et al [7] and that of Du Couëdic et al. [8].

On the other hand, the existence of simple pulmonary affections has been known since the first four German case reports published in 1943 [9] and the first two American case reports in 1953 [10]. leptospira pulmonary canicular model was identified for the first time in 1945 [11] but is less frequent. Alveolar hemorrhage and acute respiratory distress syndrome (ARDS) are two of the main death's causes [2].

The pathophysiology of pulmonary affection in leptospirosis remains controversial. Hypoxemia causes in leptospirosis may be related to cardiogenic pulmonary edema secondary to myocarditis, or related to pulmonary overload later to hypervolemia on acute renal failure [2].

Alveolar haemorrhage is the most common, but hemoptysis is not always large. Diffuse or focal intra-alveolar haemorrhages explain endothelial lesions of the capillaries [3]. During incubation period the spirochaete disperse hematogenously, adhering to epithelial cells causing severe vasculitis with endothelial rather than inflammatory lesions. Two hypotheses were also underlined, the first is a direct action of the spirochete on the membrane of parenchymal cells and the second hypothesis is an unidentified bacterial toxin that causes pulmonary capillary lesions and increases permeability [2]. Moreover, it seems on the animal model that an autoimmune phenomenon is involved with membrane deposition of $\operatorname{IgM}, \operatorname{IgA}, \operatorname{IgG}$ and C3 complement [3].
During leptospirosis, pulmonary affection affects 20 to $40 \%$ of the cases [3]. In our case report, it is a pulmonary form associated with liver failure. Respiratory signs usually include cough, dyspnea, chest pain and hemoptysis, which can be life-threatening [3].

Radiological anomalies are mainly located at the bases and at the periphery. Apical affection is more rare. Bilateral reticulonodular infiltrates related to the most frequent feature in case of pulmonary impairement $[1,3]$ as it is for our patient's case.

Miliary pulmonary x-Ray form of Leptospira canicola without clinical respiratory signs is less common; however, it has been reported [10, 12, 13] and does not seem to have any clinical expression or pejorative prognosis.

Diagnosis Confirmation is based on serology and PCR. Several serological tests are available. The reference is the agglutination reaction of Martin and Small clarified in 1918. Serum antibodies appear eight to ten days after symptoms onset: first IgM then inconsistently IgG. They decrease over three to six months, and can persist at residual levels for several years. An early test (before 8 days) is negative once in two and therefore requires another test two to three weeks later [14, 16].

The search for the genome by genomic chain amplification (PCR) makes it possible to make a specific diagnosis, fast and early, but remains less available $[2,15,16]$.

Systemic bronchoalveolar wachout revealed alveolar haemorrhage in all cases with respiratory symptomatology and in seven out of 10 patients without respiratory symptoms [2]. It was not performed in our patient because he was very dyspnetic and did not support bronchoscopy.

Antibiotherapy is typically based on penicillin $\mathrm{G}$ or doxycycline. Ceftriaxone is a recognized treatment for leptospirosis [3, 15]. The antibiogram is not performed usually because there is noregular technique Leptospires are sensitive to beta-lactams, macrolides, cyclins, fluoroquinolones and streptomycin [16].

Intra-alveolar haemorrhage with pulmonary affection involves the use of desmopressin at a dose of $0.3 \mathrm{mg} / \mathrm{kg}$ in case of large haemoptysis. Nitric oxide is a therapeutic option in severe alveolar hemorrhage [2]. Extracorporeal oxygenation is suggested for option in case of refractory hypoxemia and has already been used during leptospirosis [2].

In multivisceral dysfunction with renal affection continuous or discontinuous extrarenal treatment is frequently used $[1,2]$. Immunomodulation with high-dose corticosteroid therapy and immunoglobulin therapy improve severe leptospirosis 
[2]. Plasmapheresis has also been underlined as an adjuvant technique with good results.

This case report recalls the importance of vaccination for exposed people. The vaccine available in France (leptospira 200 MUI / ml) is effective only against the $\mathrm{L}$ form. icterohaemorrhagiae, the most serious leptospirosis forms are often due to infection with a serogroup icterohaemorrhagiae stem [17]. Nevertheless, a study Led in the region of Grand Casablanca reports that this serogroup was also the most found among exposed people [18]. Hence the interest of introducing human antileptospirosis in Morocco vaccine, not yet available.

Moreover, more and more people are exposed to this risk from their profession or their hobby activity, as was the case for our patient. Some authors suggest chemoprophylaxis, by doxycycline $200 \mathrm{mg}$, allowing $95 \%$ protection of subjects before swimming in risk water [3].

\section{CONCLUSION}

Respiratory signs may appear first during leptospirosis, and the absence of jaundice should not rule out diagnosis. Hemoptysis is the main significance of intra-alveolar haemorrhages which worsen these disorders, and lead towards respiratory distress syndrome. Their high mortality rate requires prompt care. The clinical model of febrile miliaria can be misleading and remind us of tuberculosis in our context.

Our case's report purpose is to remember that we must think of leptospirosis when ever there is pneumopathy associated with hemoptysis. The lifestyle improvement and human anti-leptospirosis vaccine introduction in Morocco is necessary allowing a better protection of risk subjects.

\section{REFERENCES}

1. Paganin F, Bourdin A, Borgherini G, Dalban C, Poubeau P, Tixier F, Gouix A, Noel JB, Cotte L, Arvin-Berod C. Manifestations pulmonaires de la leptospirose. Revue des maladies respiratoires. 2009 Nov 1;26(9):971-9.

2. Vandroux D, Bouchet B, Bossard G, Leaute B, Alves T. Atteintes respiratoires de la leptospirose. La Presse médicale (1983). 2010;39(12):1333-6.

3. Batjom E, Koulmann P, Grasser L, Rousseau JM. Une étiologie rare de syndrome de détresse respiratoire aiguë de l'adulte: la leptospirose. InAnnales françaises d'anesthésie et de réanimation 2005 Jun 1 (Vol. 24, No. 6, pp. 637-639). Elsevier Masson.

4. Nardone A, Campese C, Postic D, André-Fontaine G, Lienard M, Baranton G, Capek I. Les facteurs de risque de leptospirose en France: une étude castémoins nationale (1999). Médecine et Maladies infectieuses. 2001; 1(31):285-7.
5. Agésilas F, Gey F, Monbrunt A, Combes JC, Llanas B, Schlossmacher P, Gaüzère BA. Leptospiroses de l'enfant à l'île-de-la-Réunion: à propos de 16 cas Acute leptospirosis in children in Reunion island: a retrospective review of 16 cases. Archives de pédiatrie. 2005;12:1344-8.

6. Akoun G. A propos des déterminations pulmonaires des leptospiroses. Revue de Pneumologie Clinique. 2004 Feb 1;60(1):58.

7. El Ouazzani H, Benomar J, Soualhi M, Bouchentouf R, Bourkadi JE. Atteinte pulmonaire au cours de la leptospirose: A propos de deux cas. Revue de pneumologie clinique (Paris). 2003;59(3):155-9.

8. Couëdic L, Bouffandeau B, Ducq P, de Cagny B, Fournier A. La leptospirose: une cause rare de SDRA en France métropolitaine. Revue de pneumologie clinique (Paris). 1998;54(5):268-70.

9. Moeschlin S. Lungeninfiltrate beim Ikterus infectiosus Weil. Schwabe; 1943.

10. Silverstein, Charles M. Manifestation's pulmonaires de leptospirose. Radiology. 1953, 61(3): 327-334.

11. Bolgert M, Kolochineerber, Noel E. Une petite epidemie humaine dinfection a leptospira-canicolapremier cas. Inpresse medicale. 1945 Jan 1 53(48): 658-658. 120 BLVD SAINT-GERMAIN, 75280 PARIS 06, FRANCE: MASSON EDITEUR.

12. Thiry P, Ablard G, Larcan A. Une manifestation rare de leptospirose-la miliaire pulmonaire. Presse Medicale. 1955 Jan 1;63(35):729-30.

13. Benhamou E, Timsit M, Akoun G. Premier cas nord-africain de leptospirose canicolaire et premier cas de miliaire pulmonaire due à Leptospira canicola. Bull Mem Soc Med Hop Paris. 1955 Oct 14;71(23-24):923-30.

14. Peyrethon C. Leptospirose-quels moyens de prévention en milieu professionnel?. Archives des Maladies Professionnelles et de l'Environnement. 2012;73(1):37-47.

15. Gaillard T, Martinaud C, Faivre A, Souraud JB, Maslin J, Alla P, Brisou P. Moyens biologiques et stratégie diagnostique de la leptospirose neuroméningée. À propos d'un cas. La Revue de médecine interne. 2009 Apr 1;30(4):361-4.

16. Musso D, Lascola B. Diagnostic biologique de la leptospirose. Revue francophone des laboratoires. 2013 Feb 1;2013(449):39-46.

17. Rodriguez-Gonzalez I, Fillonneau C, Blanchet B, Suard I, Catilina P, Andre-Fontaine G. Efficacy of Spirolept vaccine against human leptospirosis as estimated by passive protection of laboratory rodents. Medecine et maladies infectieuses. 2004 May;34(5):196-200.

18. Sadat MA. Séroprévalence de la leptospirose chez les professionnels à risque, 2014, Région du Grand Casablanca, Maroc. Revue d'Épidémiologie et de Santé Publique. 2016 Sep 1;64:S206. 